\title{
INFLUÊNCIA DA PASSIVAÇÃO EM CÉLULAS SOLARES DE SILÍCIO COM CAMPO RETRODIFUSOR SELETIVO DE ALUMÍNIO E BORO
}

\author{
Thais Crestani ' \\ Izete Zanesco ' \\ Adriano Moehlecke '
}

\section{Resumo}

O campo retrodifusor seletivo em células solares processadas em lâminas de silício tipo p possibilita aumentar a eficiência, ao mesmo tempo em que evita o abaulamento, típico em células solares com campo retrodifusor homogêneo formado por pasta de alumínio. O objetivo deste trabalho é analisar a influência da passivação com $\mathrm{SiO}_{2}$ no emissor de fósforo e no campo retrodifusor seletivo de alumínio e boro de células solares $\mathrm{n}^{+} \mathrm{pp}^{+}$processadas em lâminas de silício Czochralski tipo p, grau solar. O campo retrodifusor seletivo foi formado pela difusão de boro em toda a face posterior da lâmina de silício e por serigrafia foi depositada a pasta de alumínio, somente nas trilhas metálicas. Para a temperatura de difusão de boro $\left(T_{B}\right)$ de $950^{\circ} \mathrm{C}$, observou-se que a passivação resultou em um aumento da eficiência devido ao aumento da tensão de circuito aberto e que a passivação somente foi eficaz no emissor $n^{+}$. Para a $T_{B}$ de $970^{\circ} \mathrm{C}$, as células solares com passivação alcançaram a eficiência de $16,0 \%$, devido ao aumento no fator de forma e a passivação foi eficaz na região $\mathrm{p}^{+}$dopada com boro e no emissor de fósforo.

Palavras-chave: Células solares; Campo retrodifusor seletivo; Passivação.

\section{INFLUENCE OF THE PASSIVATION IN SILICON CELLS SOLAR WITH SELECTIVE BACK SURFACE FIELD OF ALUMINIUM AND BORON}

\begin{abstract}
The selective back surface field in solar cells processed in p-type silicon wafers enables the increasing of the efficiency and avoids the typical bowing in solar cells with homogeneous back surface field formed by aluminum paste. The goal of this paper is to analyze the influence of passivation with $\mathrm{SiO}_{2}$ in the phosphorus emitter and in the selective back surface field of aluminum and boron of $\mathrm{n}^{+} \mathrm{pp}^{+}$solar cells processed in $\mathrm{p}$-type Czochralski silicon wafers, solar grade. The selective back surface field was formed by boron diffusion in whole rear face of the silicon wafer and the aluminum paste was deposited by screen printing to form the metal grid and the selective emitter. Solar cells were processed with boron diffusion temperature $\left(T_{B}\right)$ of $950^{\circ} \mathrm{C}$. The passivation enhanced the efficiency due to the increase of the open circuit voltage and the passivation is effective only in the emitter. The solar cells produced with $T_{B}$ of $970^{\circ} \mathrm{C}$ and passivation achieved the efficiency of $16.0 \%$, due to the increasing of the fill factor. Analyzing these devices, we also concluded that the passivation was effective in the $\mathrm{p}^{+}$region, doped with boron, as well as in the phosphorus emitter.
\end{abstract}

Keywords: Solar cells; Selective BSF; Passivation.

\section{INTRODUÇÃO}

As células solares fabricadas em lâminas de silício cristalino tipo $p$ dominam o mercado mundial. As células típicas da indústria possuem uma junção pn em uma das faces e na outra face é formado o campo retrodifusor, também denominado de BSF (back surface field), que tem a função de diminuir a recombinação em superfície na face posterior da célula solar e, consequentemente, aumentar a tensão de circuito aberto e a corrente de curto-circuito [1]. Simulações mostraram que em células solares com BSF a $V_{\text {OC }}$ é pouco dependente da resistividade, mas a $J_{S C}$ aumenta com 0 aumento da resistividade da lâmina de silício [2].

O campo retrodifusor é formado por meio da difusão de boro ou alumínio em lâminas de silício tipo $p$, que forma um campo elétrico que repele os portadores de

'Núcleo de Tecnologia em Energia Solar, Programa de Pós-graduação em Engenharia e Tecnologia de Materiais, Faculdade de Física, Pontifícia Universidade Católica do Rio Grande do Sul - PUCRS, Porto Alegre, RS, Brasil. E-mail: izete@pucrs.br 
carga minoritários que se aproximam da superfície posterior, impedindo que se recombinem.

Em células solares com estrutura $\mathrm{n}^{+} \mathrm{pp}^{+}$e com BSF homogêneo, a formação de uma região $\mathrm{p}^{+}$altamente dopada na superfície posterior depende dos seguintes parâmetros [3]:

- Da concentração superficial do dopante na região $\mathrm{P}^{+}$e da concentração do dopante em função da profundidade;

- Da recombinação na própria camada $\mathrm{p}^{+}$; e

- Da relação entre o comprimento de difusão dos portadores de carga minoritários e a espessura da lâmina de silício.

O desenvolvimento do campo retrodifusor seletivo de alumínio e boro em células solares processadas em lâminas de silício tipo $\mathrm{p}$ possibilita aumentar a eficiência, ao mesmo tempo em que evita o abaulamento, típico em células solares com BSF homogêneo formado por pasta de alumínio [4]. A face posterior da célula solar típica da indústria é completamente recoberta com pasta de alumínio, que provoca o abaulamento, devido aos diferentes coeficientes de dilatação do silício e da pasta de alumínio. Neste caso, tem-se uma superfície com alta velocidade de recombinação dos portadores de carga minoritários, devido ao contato metal-semicondutor [5].

A formação do emissor seletivo pode proporciona um aumento de $0,3 \%$ a $2 \%$ na eficiência em relação ao padrão de células solares com emissor homogêneo, dependendo de outras etapas do processo, tais como passivação e metalização, entre outras. A eficiência das células solares com emissor seletivo também é maior, se comparada com a eficiência de dispositivos com emissor localizado [6].

Para se obter uma célula solar de silício com alta eficiência (maior ou igual a 20\%) é importante passivar ambas as faces do dispositivo. A passivação consiste em diversos métodos que têm como objetivo reduzir a recombinação dos portadores de carga minoritários nas superficies. Portanto, a passivação eficaz é uma forma de reduzir o custo das células solares por meio do aumento da eficiência. Atualmente, um dos desafios para a produção de células solares comerciais é baixar o custo de produção. Neste sentido, os métodos de passivação a baixas temperaturas estão se tornando cada vez mais utilizados [7]. Na indústria utiliza-se o nitreto de silício.

O óxido de silício é um dielétrico eficaz para passivar a superfície de células solares de silício, porém o processo a alta temperatura para crescer $\mathrm{SiO}_{2}$ pode provocar a contaminação do substrato por metais, degradando o tempo de vida dos portadores minoritários. Uma alternativa é depositar uma fina camada de nitreto de silício $\left(\mathrm{SiN}_{\mathrm{x}}\right)$ por PECVD (plasma-enhanced chemical vapor deposition) com temperaturas menores que $500^{\circ} \mathrm{C}[8]$. O SiN ${ }_{x}$ serve como filme antirreflexo em células solares, e também como material para passivar a superfície de silício do tipo n. Porém, a passivação com $\mathrm{SiN}_{\mathrm{x}}$ é menos eficiente para a superfície de silício tipo p. Recentemente a utilização de deposição de camadas atômicas (ALD - atomic layer deposition) de um filme fino de $\mathrm{Al}_{2} \mathrm{O}_{3}$ tem se mostrado mais eficiente em lâminas de silício tipo $p$ [9]. Dispositivos com área de $156 \mathrm{~mm} \times 156 \mathrm{~mm}$ foram desenvolvidos com deposição por $A L D$ de $\mathrm{Al}_{2} \mathrm{O}_{3}$ em células solares do tipo PERC (passivated emitter and rear contacts) e foi obtido um aumento na eficiência de $0,7 \%$ absoluto [ 10$]$.

Um método padrão de passivação da superfície de lâminas de silício é a oxidação térmica a alta temperatura $\left(\sim 1000^{\circ} \mathrm{C}\right)$. O óxido de silício formado termicamente proporciona excelente passivação de superfície em lâminas de silício tipo $\mathrm{n}$ e tipo $\mathrm{p}$ de alta resistividade $(>100 \Omega . \mathrm{cm})$. Contudo, para resistividades baixas $(\sim \mid \Omega . \mathrm{cm})$ a qualidade da passivação depende do tipo de dopagem que a lâmina foi submetida [8].

Células solares com $20 \%$ de eficiência, com BSF de boro, foram obtidas no trabalho desenvolvido por Das et al. [II], no qual foi realizada a formação de uma camada dielétrica de $\mathrm{SiO}_{2}$, por spin-on, que realiza tanto gettering de impurezas indesejadas quanto a passivação de superfície em uma única etapa térmica. Alta densidade superficial de cargas elétricas, da ordem de $10^{3} \mathrm{~cm}^{-2}$, foi encontrada o que explica a qualidade da passivação na superfície [II]. Yang et al. [12] analisaram a influência da passivação formada por uma camada de $\mathrm{SiO}_{2} / \mathrm{a}-\mathrm{Si}: \mathrm{H}$ em células solares IBC (interdigitated back contact) base $\mathrm{n}$ com dopagem a laser nas regiões $\mathrm{p}^{+}$e $\mathrm{n}^{+}$e obtiveram a eficiência de $23 \%$ em lâminas de Si crescido por fusão zonal flutuante (Si-FZ). Nestes dispositivos, o alumínio foi depositado pelo método de evaporação em alto vácuo [12].

O óxido de silício pode ser depositado em ambas as faces da lâmina no mesmo processo térmico e foi comprovado que este dielétrico é eficaz na passivação de regiões altamente dopadas tipo $\mathrm{n}$ e tipo $\mathrm{p}$. Em trabalhos anteriores foi constatado que uma camada de $10 \mathrm{~nm}$ de $\mathrm{SiO}_{2}$ é eficaz em passivar a região altamente dopada $\mathrm{n}^{+} \mathrm{com}$ fósforo [13].

O objetivo deste trabalho é analisar a influência da passivação com $\mathrm{SiO}_{2}$ em ambas as faces de células solares com campo retrodifusor seletivo de alumínio e boro processadas em lâminas de silício Czochralski (Si-Cz) tipo p, grau solar. Para formar o campo retrodifusor seletivo, a difusão de boro foi implementada em toda a face posterior da lâmina de silício e por serigrafia foi depositada a pasta de alumínio, somente nas trilhas metálicas [14]. A inovação está focada na eficâcia da passivação do campo retrodifusor $\mathrm{p}^{+}$por meio de uma fina camada de $10 \mathrm{~nm}$ de $\mathrm{SiO}_{2}$, produzida por oxidação seca. Portanto, este processo pode ser facilmente adaptado à indústria atual de células solares.

\section{MATERIAIS E MÉTODOS}

O processo de fabricação das células solares com passivação está resumido na Figura I e consistiu basicamente nas seguintes etapas: texturação das superfícies das lâminas de Si, limpeza química RCA2 [15], difusão de boro e oxidação na mesma etapa térmica [16], ataque em ácido fluorídrico 
e limpeza RCA, difusão de fósforo, ataque do silicato de boro e de fósforo e limpeza química RCA2, crescimento de $\mathrm{SiO}_{2}$ (oxidação térmica seca), deposição do filme antirreflexo $(A R)$, metalização na face frontal e posterior por serigrafia $\mathrm{e}$ isolamento das bordas. As células solares sem passivação foram produzidas pelo mesmo processo, porém sem a etapa de crescimento de $\mathrm{SiO}_{2}$. Destaca-se que está sendo solicitada a patente, junto ao INPI (Instituto Nacional de Propriedade Industrial) de etapas deste processo de produção de células solares [17]. Utilizaram-se substratos de $\mathrm{Si}-\mathrm{Cz}$ tipo p, grau solar, com 100 mm de diâmetro, espessura de $(200 \pm 30) \mu \mathrm{m}$, orientação dos planos cristalinos $\{100\}$ e resistividade de base entre I $\Omega . \mathrm{cm}$ e $20 \Omega . \mathrm{cm}$.

Neste caso, o campo retrodifusor seletivo na face posterior foi formado por boro entre as trilhas metálicas e alumínio sob as trilhas metálicas. A difusão de alumínio ocorreu durante o processo de queima simultâneo das pastas metálicas depositadas em ambas as faces. A região $\mathrm{p}^{+}$com boro foi formada pela deposição do líquido dopante PBF20 e a difusão foi realizada em forno com tubo de quartzo. A difusão de boro foi realizada para a temperatura $\left(T_{B}\right)$ de $950^{\circ} \mathrm{Ce} 970^{\circ} \mathrm{C}$, que resultou na resistência de folha da região $\mathrm{p}^{+}\left(\mathrm{R} \square_{\text {Boro }}\right)$ entre $52 \Omega / \square$ e $56 \Omega / \square$, para a $T_{B}=950^{\circ} \mathrm{C}$, como mostra a Tabela I. A resistência de folha foi medida em I 3 regiões da lâmina de silício. Com o aumento da $T_{B}$ para $970^{\circ} \mathrm{C}$, a resistência de folha diminuiu e foi de $42-43 \Omega / \square$. Para os processos com passivação de superfícies a resistência de folha foi medida antes da oxidação seca.

No campo retrodifusor seletivo foi formada uma região menos dopada entre as trilhas metálicas, reduzindo-se a recombinação dos portadores de carga minoritários e uma região mais dopada sob as trilhas metálicas, que reduz a resistência de contato. Ao mesmo tempo, o campo retrodifusor seletivo de boro e alumínio evita o abaulamento das células solares.

Após a difusão de boro e oxidação, limpeza química em ácido fluorídrico e em solução RCA2, foi implementada a difusão de fósforo na face frontal em forno com tubo de quartzo com o dopante $\mathrm{POCl}_{3}$. Como se pode ver na Tabela I, a resistência de folha do emissor de fósforo variou de $54 \Omega / \square$ a $60 \Omega / \square$.

$\mathrm{O}$ filme antirreflexo de $\mathrm{TiO}_{2}$ na face frontal foi depositado em vácuo pela técnica de canhão de elétrons, após a limpeza química RCA2 e antes do processo de deposição das pastas metálicas para a formação do BSF seletivo e da malha metálica frontal. A espessura do filme AR de dióxido de titânio na face frontal foi de $60 \mathrm{~nm}$.

A malha metálica posterior, que forma o BSF seletivo, foi depositada por serigrafia. $O$ recobrimento da malha de pasta de alumínio foi de $18,5 \%$ da área. A malha metálica frontal foi formada com pasta de prata e o fator de sombra foi de $7,9 \%$. A secagem e queima das pastas metálicas foi realizada em forno de esteira. A temperatura de queima (firing) das pastas metálicas e difusão de Al foi variada de $850^{\circ} \mathrm{C}$ a $890^{\circ} \mathrm{C}$.

A estrutura $\mathrm{n}^{+} \mathrm{pp}^{+}$formada por esse processo de produção de células solares com campo retrodifusor seletivo é mostrada na Figura 2, onde se destaca que a região $\mathrm{P}^{+}$seletiva foi formada pela difusão de boro e alumínio e o emissor $\mathrm{n}^{+}$foi formado pela difusão de fósforo.

As células solares foram caracterizadas por meio da medição da densidade de corrente em função da tensão elétrica aplicada (curva J-V) em condições padrão de medição: irradiância de $100 \mathrm{~mW} / \mathrm{cm}^{2}$, espectro solar AMI,5G e temperatura

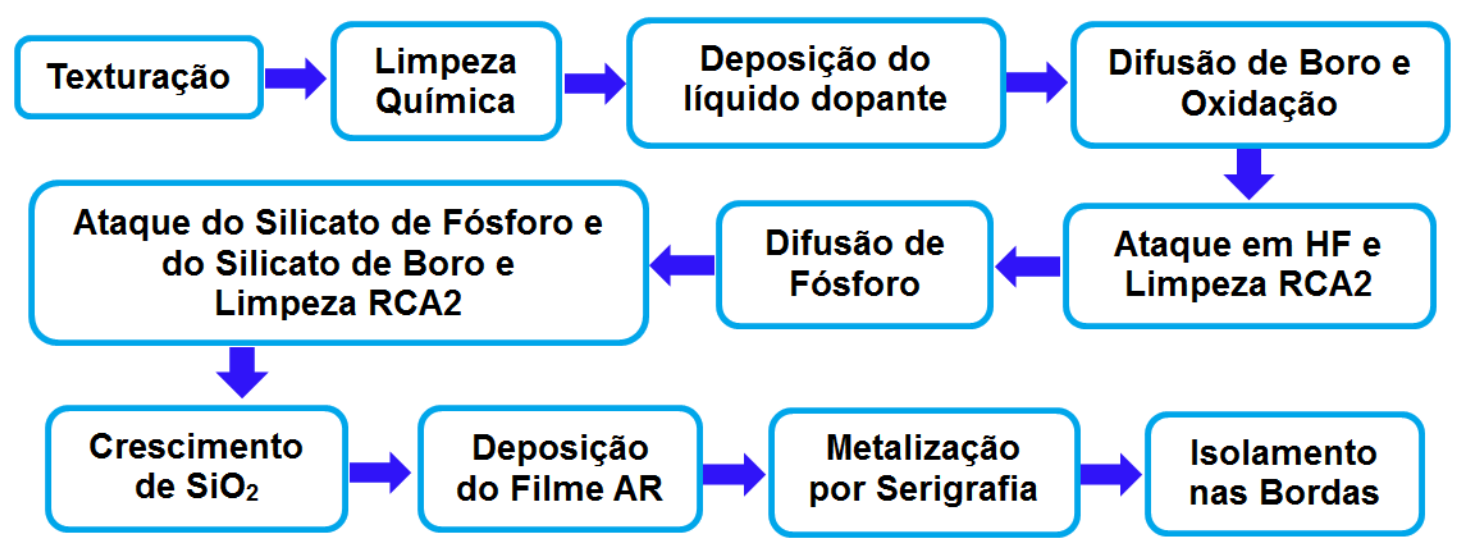

Figura I. Etapas do processo de fabricação das células solares com passivação por dióxido de silício crescido termicamente.

Tabela I. Resistência de folha da região $\mathrm{p}^{+}$com a temperatura de difusão de boro de $950^{\circ} \mathrm{C}$ e $970^{\circ} \mathrm{C}$ para as células solares processadas com e sem passivação

\begin{tabular}{|c|c|c|c|c|}
\hline \multirow{2}{*}{$\mathrm{T}_{\mathrm{B}}\left({ }^{\circ} \mathrm{C}\right)$} & \multicolumn{2}{|c|}{ Sem Passivação } & \multicolumn{2}{|c|}{ Com Passivação } \\
\hline & $\mathbf{R}_{\square_{\text {Boro }}}(\Omega / \square)$ & $\mathbf{R}_{\square_{\text {Fósforo }}}(\Omega / \square)$ & $\mathbf{R}_{\square_{\text {Boro }}}(\Omega / \square)$ & $\mathbf{R}_{\square_{\text {Fósforo }}}(\Omega / \square)$ \\
\hline 950 & $56 \pm 2$ & $60 \pm 4$ & $52 \pm 3$ & $54 \pm 6$ \\
\hline 970 & $43 \pm 2$ & $57 \pm 7$ & $42 \pm 2$ & $60 \pm 4$ \\
\hline
\end{tabular}




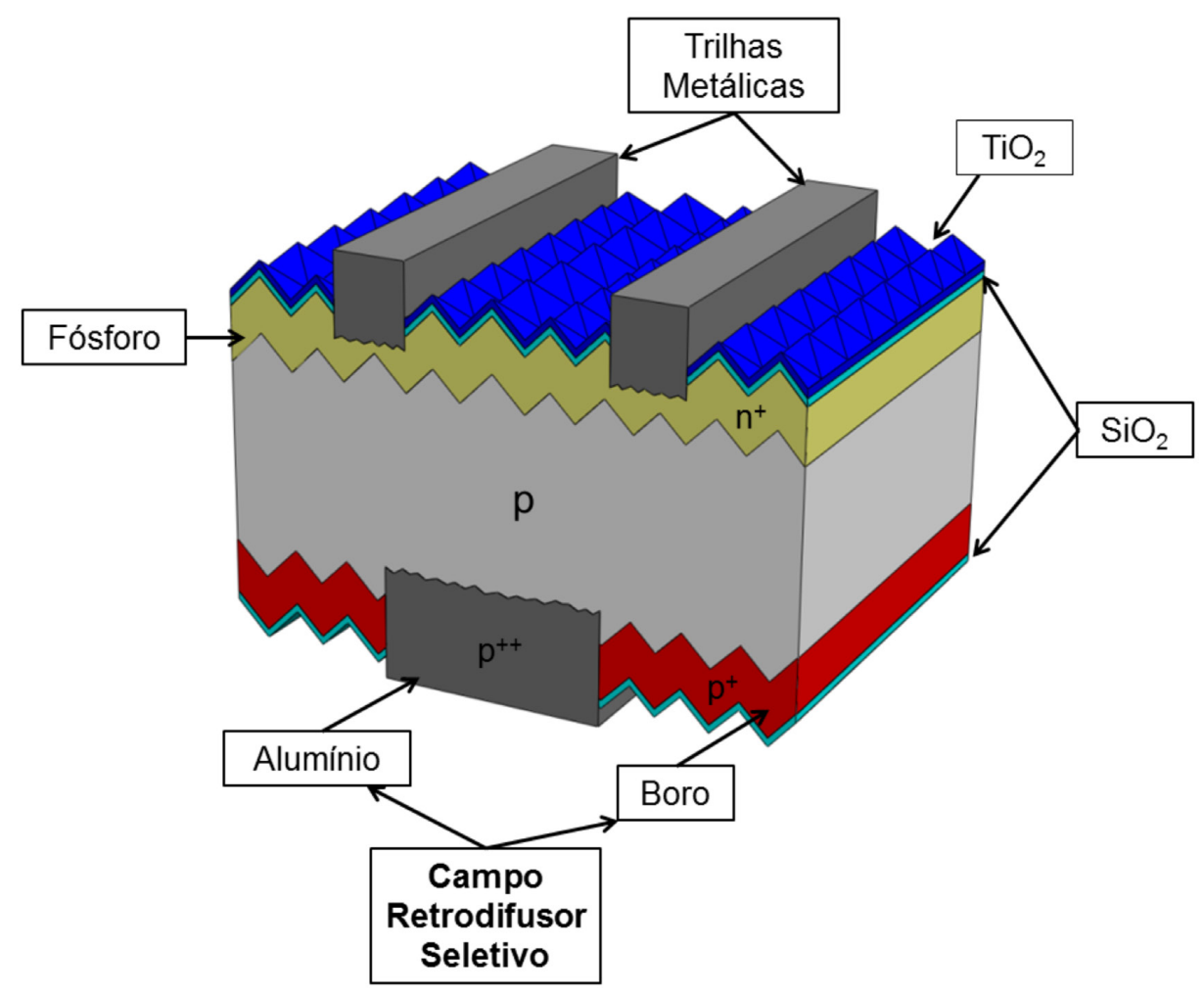

Figura 2. Estrutura da célula solar com campo retrodifusor seletivo de alumínio e boro.

da célula solar de $25^{\circ} \mathrm{C}$. Uma célula solar previamente calibrada no CalLab - FhG-ISE (Fraunhofer-Institut für Solare Energiesysteme), Alemanha, foi usada como referência. Também se mediu a resposta espectral e a refletância para avaliar a eficiência quântica interna.

\section{RESULTADOS E DISCUSSÃO}

\section{I Temperatura de Difusão de Boro de $950^{\circ} \mathrm{C}$}

Para comparar os parâmetros elétricos de células solares com e sem passivação com $\mathrm{SiO}_{2}$, primeiramente realizou-se a difusão de boro a $950^{\circ} \mathrm{C}$ durante 20 minutos [I5]. Os valores médios da tensão de circuito aberto $\left(\mathrm{V}_{\mathrm{OC}}\right)$, da densidade de corrente de curto-circuito $\left(J_{\mathrm{SC}}\right)$, do fator de forma (FF) e da eficiência ( $\eta$ ) são apresentados na Tabela 2, onde $T_{Q}$ é a temperatura de queima simultânea da pasta de alumínio que forma a malha na face posterior e da pasta de prata, que forma a malha metálica na face frontal.

Da Tabela 2 pode-se observar que as células solares com passivação resultaram em um aumento da eficiência devido ao aumento da $\mathrm{V}_{\mathrm{OC}}$ em todas as temperaturas de queima/difusão. Sem passivação, a melhor eficiência média foi de $(15,1 \pm 0,4) \%$ e foi obtida para a temperatura de queima de $880^{\circ} \mathrm{C}$, com $\mathrm{V}_{\text {oc }}$ média de $(584,0 \pm \mathrm{I}, 4) \mathrm{mV}$. Para os dispositivos com passivação, a maior eficiência média, de $(15,6 \pm 0, I) \%$, também foi obtida para a temperatura de queima de $880^{\circ} \mathrm{C}$. Neste caso, $\mathrm{V}_{\mathrm{OC}}$ média foi de $(593, \mathrm{I} \pm \mathrm{I}, \mathrm{I}) \mathrm{mV}$. Também se nota que o desvio padrão da eficiência diminuiu um pouco com a passivação. Nos dispositivos sem passivação o fator de forma aumentou com o aumento da temperatura de queima. Porém, nas células solares com passivação não se observou esta dependência, pois o fator de forma foi maior, da ordem de 0,77. A $J_{s C}$ praticamente não foi afetada pela passivação.

$\mathrm{Na}$ Figura 3 apresenta-se a eficiência quântica interna (EQI) das células solares com maior eficiência de conversão de energia solar em elétrica. Neste caso, a eficiência foi de 15,6\% para a célula solar com e sem passivação. Observa-se que o processo com passivação com $\mathrm{SiO}_{2}$ promoveu um aumento da $\mathrm{EQI}$ principalmente para comprimentos de onda menores que $600 \mathrm{~nm}$. Este resultado indica que a passivação é mais efetiva no emissor de fósforo que na região $\mathrm{p}^{+}$do campo retrodifusor seletivo, para a temperatura de difusão de boro de $950^{\circ} \mathrm{C}$.

\subsection{Temperatura de Difusão de Boro de $970^{\circ} \mathrm{C}$}

Para comparar a influência da passivação em células solares com a região $\mathrm{p}^{+}$mais profunda entre as trilhas metálicas, processaram-se dispositivos com temperatura de difusão de boro de $970^{\circ} \mathrm{C}$ durante 20 minutos. Os parâmetros elétricos médios das células solares com e sem passivação são mostrados na Tabela 3. 
Tabela 2. Parâmetros elétricos médios das células solares com e sem passivação com $\mathrm{SiO}_{2}$ processadas com temperatura de difusão de boro de $950^{\circ} \mathrm{C}$ em função da temperatura de queima das pastas metálicas

\begin{tabular}{|c|c|c|c|c|c|c|}
\hline Passivação & $\mathbf{N}^{\circ}$ de células & $\mathrm{T}_{\mathrm{Q}}\left({ }^{\circ} \mathrm{C}\right)$ & $\mathbf{V}_{\mathrm{oc}}(\mathrm{mV})$ & $J_{s c}\left(m A / c^{2}\right)$ & $\mathbf{F F}$ & $\eta(\%)$ \\
\hline \multirow{4}{*}{$\mathrm{Sem} \mathrm{SiO}_{2}$} & 2 & 850 & $587,6 \pm 0,5$ & 33,8 & $0,749 \pm 0,001$ & 14,9* \\
\hline & 4 & 860 & $585,9 \pm 0,6$ & $33,7 \pm 0,1$ & $0,759 \pm 0,007$ & $15,0 \pm 0,1$ \\
\hline & 5 & 870 & $583,5 \pm 1,4$ & $33,9 \pm 0,1$ & $0,752 \pm 0,009$ & $14,9 \pm 0,2$ \\
\hline & 4 & 880 & $584,0 \pm 1,4$ & $33,8 \pm 0,1$ & $0,767 \pm 0,016$ & $|5| \pm 0,4$, \\
\hline \multirow{3}{*}{$\mathrm{Com} \mathrm{SiO}_{2}$} & 5 & 860 & $593,0 \pm 0,7$ & $33,7 \pm 0,1$ & $0,771 \pm 0,013$ & $15,4 \pm 0,2$ \\
\hline & 5 & 870 & $594,0 \pm 1,1$ & $33,7 \pm 0,2$ & $0,777 \pm 0,003$ & $15,5 \pm 0,1$ \\
\hline & 4 & 880 & $593, I \pm I, I$ & $33,8 \pm 0,2$ & $0,774 \pm 0,005$ & $15,6 \pm 0, \mid$ \\
\hline
\end{tabular}

* As duas células solares apresentam o mesmo valor de eficiência e $J_{\mathrm{SC}}$.

Tabela 3. Parâmetros elétricos médios das células solares com e sem passivação com $\mathrm{SiO}_{2}$ processadas com temperatura de difusão de boro de $970^{\circ} \mathrm{C}$ em função da temperatura de queima das pastas metálicas

\begin{tabular}{|c|c|c|c|c|c|c|}
\hline Passivação & $\mathbf{N}^{\circ}$ de células & $\mathrm{T}_{\mathrm{Q}}\left({ }^{\circ} \mathrm{C}\right)$ & $\mathbf{V}_{\text {oc }}(\mathrm{mV})$ & $J_{s c}\left(m A / c m^{2}\right)$ & $\mathbf{F F}$ & $\eta(\%)$ \\
\hline \multirow{4}{*}{$\mathrm{Sem} \mathrm{SiO}_{2}$} & 4 & 850 & $592,5 \pm 0,6$ & $33,9 \pm 0,1$ & $0,737 \pm 0,035$ & $14,3 \pm 0,6$ \\
\hline & 4 & 860 & $591,8 \pm 1,0$ & $33,7 \pm 0,1$ & $0,762 \pm 0,010$ & $14,7 \pm 0,2$ \\
\hline & 5 & 870 & $590,0 \pm 1,6$ & $33,9 \pm 0,1$ & $0,762 \pm 0,018$ & $14,8 \pm 0,4$ \\
\hline & 4 & 880 & $588,7 \pm 0,4$ & $33,8 \pm 0,1$ & $0,758 \pm 0,006$ & $14,6 \pm 0,2$ \\
\hline \multirow{5}{*}{$\mathrm{Com} \mathrm{SiO}_{2}$} & 3 & 850 & $591,0 \pm 0,1$ & $33,6 \pm 0,1$ & $0,789 \pm 0,026$ & $15,7 \pm 0,6$ \\
\hline & 3 & 860 & $590,8 \pm 0,4$ & $33,7 \pm 0,1$ & $0,793 \pm 0,015$ & $15,8 \pm 0,4$ \\
\hline & 3 & 870 & $590,5 \pm 0,4$ & $33,8 \pm 0,1$ & $0,790 \pm 0,008$ & $15,8 \pm 0,1$ \\
\hline & 3 & 880 & $589,1 \pm 0,5$ & $33,8 \pm 0,1$ & $0,780 \pm 0,005$ & $15,6 \pm 0,1$ \\
\hline & 3 & 890 & $589,6 \pm 0,5$ & $33,9 \pm 0,1$ & $0,790 \pm 0,002$ & $15,8 \pm 0,1$ \\
\hline
\end{tabular}

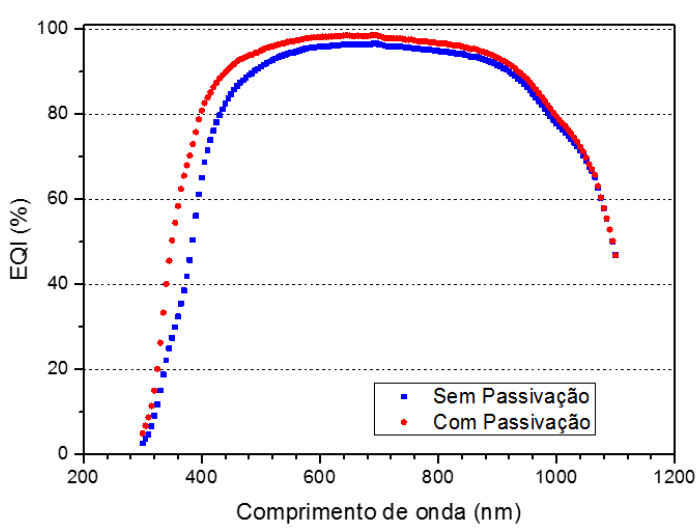

Figura 3. Eficiência quântica interna das células solares produzidas com temperatura de difusão de boro de $950^{\circ} \mathrm{C}$, com e sem passivação das superfícies com $\mathrm{SiO}_{2}$.

A maior eficiência média medida em dispositivos sem passivação foi de $(\mid 4,8 \pm 0,4) \%$, obtida com a temperatura de queima de $870^{\circ} \mathrm{C}$. Novamente, verifica-se que o menor FF ocorreu para a menor $T_{Q}$. Com a passivação, a eficiência média aumentou para $15,8 \%$ e ocorreu para as temperaturas de queima de $860^{\circ} \mathrm{C}, 870^{\circ} \mathrm{C}$ e $890^{\circ} \mathrm{C}$. Comparando a Tabela 3 com a Tabela 2, nos dispositivos sem passivação, a $\mathrm{V}_{\mathrm{OC}}$ aumentou devido a maior profundidade da região $\mathrm{p}^{+}$formada pela difusão de boro.

A célula de maior eficiência sem passivação apresentou $\mathrm{V}_{\mathrm{OC}}=590,0 \mathrm{mV}, \mathrm{J}_{\mathrm{sC}}=33,9 \mathrm{~mA} / \mathrm{cm}^{2}$,
$\mathrm{FF}=0,779$ e $\eta=15,6 \%$. Com passivação, o dispositivo mais eficiente apresentou os seguintes parâmetros elétricos: $\mathrm{V}_{\mathrm{oC}}=590,9 \mathrm{mV}, \mathrm{J}_{\mathrm{sC}}=33,5 \mathrm{~mA} / \mathrm{cm}^{2}, \mathrm{FF}=0,806 \mathrm{e} \eta=16,0 \%$. Neste caso, a eficiência aumentou devido ao aumento do fator de forma. $A V_{o c}$ aumentou pouco. Portanto, comprova-se que além de aumentar $a V_{o c}$, a passivação também aumenta o fator de forma.

A eficiência quântica interna para as células solares com maior eficiência, com e sem passivação com $\mathrm{SiO}_{2}$, é comparada na Figura 4a. Na Figura $4 \mathrm{~b}$ mostra-se a refletância das mesmas células solares. Observa-se que a passivação promove um aumento da EQI, tanto para comprimentos de onda curtos, quanto para comprimentos de onda maiores que $900 \mathrm{~nm}$. Portanto, pode-se concluir que quando a região $\mathrm{P}^{+}$dopada com boro do BSF seletivo tem menor resistência de folha (maior profundidade) a passivação com $\mathrm{SiO}_{2}$ nesta região é eficaz.

$A \int_{s C}$ da célula com maior eficiência e sem passivação foi de $33,9 \mathrm{~mA} / \mathrm{cm}^{2}$ e para a célula com passivação foi de $33,5 \mathrm{~mA} / \mathrm{cm}^{2}$, devido ao aumento da refletância para comprimentos de onda menores que $600 \mathrm{~nm}$, como mostra a Figura 4b. Este resultado indica que o filme de dióxido de titânio deve ser otimizado para dispositivos com passivação. A espessura do filme $A R$ para a célula sem passivação foi de $65 \mathrm{~nm}$ e para a célula com passivação $\left(\mathrm{SiO}_{2}\right.$ e $\left.\mathrm{TiO}_{2}\right)$ foi de $73 \mathrm{~nm}$. Estes valores foram estimados a partir da medida da refletância. 


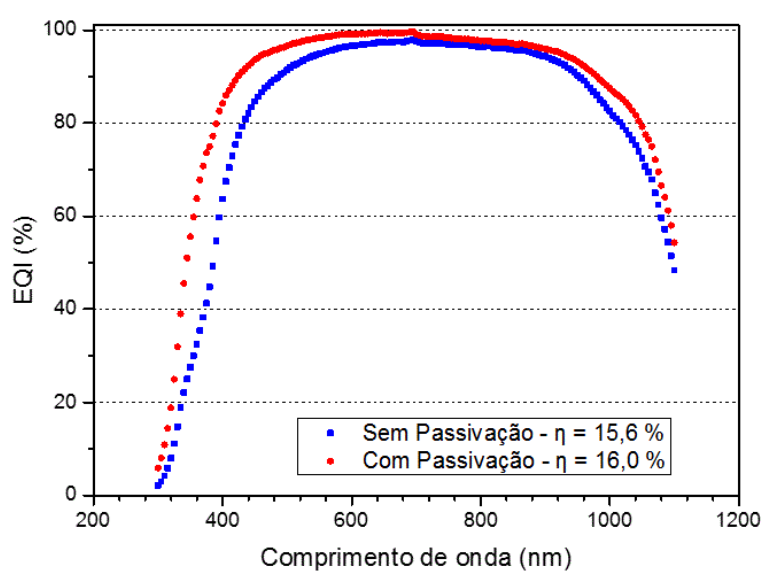

(a)

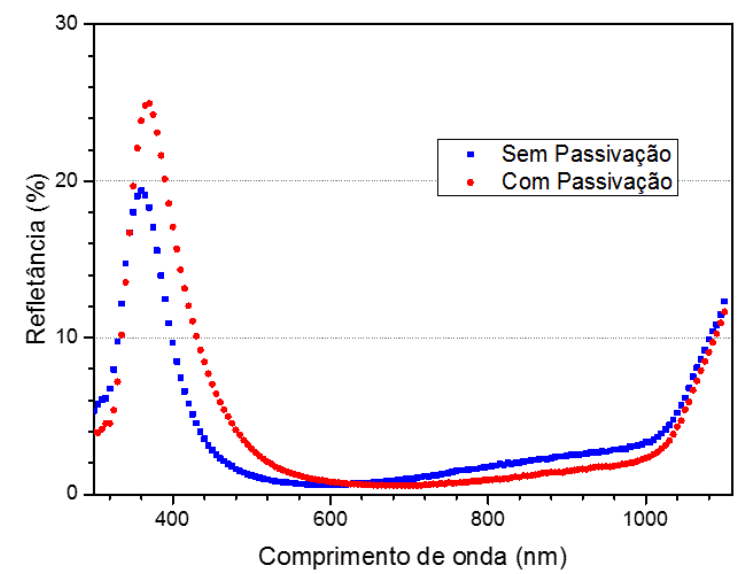

(b)

Figura 4. (a) Eficiência quântica interna; e (b) refletância das células solares produzidas com temperatura de difusão de boro de $970^{\circ} \mathrm{C}$, com e sem passivação de superfícies com $\mathrm{SiO}_{2}$.

A refletância média ponderada $\left(\rho_{w}\right)$ considera a sensibilidade espectral da célula solar e o espectro solar e é calculada como segue [18]:

$$
\rho_{w}=\left(\int E s(\lambda) R E(\lambda) \rho(\lambda) d \lambda / \int E s(\lambda) R E(\lambda) d \lambda\right)(
$$

onde, $E s(\lambda)$ é o espectro solar AMI,5G, $R E(\lambda)$ é a resposta espectral e $\rho(\lambda)$ é a refletância. A refletância média ponderada foi de $2,5 \%$ e $2,6 \%$ para a célula sem e com passivação, respectivamente, justificando a menor $J_{S C}$ para a célula solar com passivação. Considerou-se a refletância em amostras sem metalização.

\section{CONCLUSÕES}

Foram fabricadas e caracterizadas células solares em lâminas de Si Czochralski tipo p, grau solar, com o objetivo de analisar a influência da passivação no emissor e no campo retrodifusor seletivo de alumínio e boro.

Para a temperatura de difusão de boro de $950^{\circ} \mathrm{C}$, em células solares com passivação observou-se o aumento da eficiência devido ao aumento $d a V_{\text {oc }}$ para todas as temperaturas de queima/difusão. Em células solares processadas sem passivação a melhor eficiência média foi de $(15,2 \pm 0,3) \%$ e em dispositivos com passivação a eficiência média foi de $(15,5 \pm 0,1) \%$. Também se constatou- que a passivação é mais eficaz no emissor $\mathrm{n}^{+}$que na região $\mathrm{p}^{+}$dopada com boro.

Para a temperatura de difusão de boro de $970^{\circ} \mathrm{C}$, comparando os resultados com e sem passivação, observou-se o aumento da eficiência devido principalmente ao aumento do fator de forma. As células solares com passivação alcançaram a eficiência de $16,0 \%$, ou seja, $0,7 \%$ (absoluto) maior que a eficiência dos dispositivos sem passivação. Para a região $\mathrm{P}^{+}$dopada com boro com maior profundidade, constatou-se que $\circ$ processo com passivação com $\mathrm{SiO}_{2}$ promoveu um aumento da eficiência quântica interna, tanto para comprimentos de onda curtos, quanto para comprimentos de onda maiores que $900 \mathrm{~nm}$, indicando que para a região $\mathrm{P}^{+}$com maior dopagem, a passivação com $\mathrm{SiO}_{2}$ é eficaz.

\section{Agradecimentos}

Os autores agradecem à Eletrosul pela subvenção do projeto de P\&D intitulado "Desenvolvimento de Processos Industriais para Fabricação de Células Solares com Pasta de Alumínio e Passivação", Convênio ELETROSUL n I I I I 01400 I0 e ao Conselho Nacional de Desenvolvimento Científico e Tecnológico (CNPq).

\section{REFERÊNCIAS}

I Roos VO. A simple theory of back surface field (BSF) solar cells. Journal of Applied Physics. 1978;49(6):3503-35I I. http://dx.doi.org// 0.1063/1.325262.

2 Park S, Park H, Kang Y, Lee HS, Kim D. Analysis of aluminum back surface field at different wafer specifications in crystalline silicon solar cells. Current Applied Physics. 2016;16(9): I062-1068. http://dx.doi.org/10.1016/j. cap.2016.05.016.

$3 \mathrm{Gu}$ X, Yu X, Yang D. Efficiency improvement of crystalline silicon solar cells with a back surface field produced by boron and aluminum co-doping. Scripta Materialia. 20I 2;66:394-397. 
4 Hilali MM, Gee JM, Hacke P. Bow in screen-printed back-contact industrial silicon solar cells. Solar Energy Materials and Solar Cells. 2007;91:1228-1233.

5 Green MA. Solar cells: operating principles, technology and system applications. Kensington: NSW; 1992.

6 Rahman MZ. Status of selective emitters for p-type c-Si solar cells. Optics and Photonics Journal. 2012;2(02): 129 134. http://dx.doi.org/I0.4236/opj.2012.22018.

7 Green MA. The path to $25 \%$ silicon solar cell efficiency: history of silicon cell evolution. Progress in Photovoltaics: Research and Applications. 2009;17(3):183-189. http://dx.doi.org/10.1002/pip.892.

8 Aberle AG. Surface passivation of crystalline silicon solar cells: a review. Progress in Photovoltaics: Research and Applications. 1999;8:362-376.

9 Lei D, Yu X, Song L, Gu X, Li G, Yang D. Modulation of atomic-layer-deposited Al2O3 film passivation of silicon surface by rapid thermal processing. Applied Physics Letters. 201 I;99(5): I-4. http://dx.doi.org/I0.1063/I.3616I45.

10 Cho YJ, Shin WC, Chang HS. Selective deposition contact patterning using atomic layer deposition for the fabrication of crystalline silicon solar cells. Thin Solid Films. 2014;568: I-5. http://dx.doi.org//0.1016/j. tsf.20।4.07.054.

II Das A, Meemongkolkiat V, Kim DS, Ramanathan S, Rohatgi A. 20\% efficient screen-printed cells with spin-ondielectric-passivated boron back-surface field. IEEE Transactions on Electron Devices. 20 10;57(I0):2462-2469. http://dx.doi.org/10.1 109/TED.2010.2057010.

12 Yang X, Bullock J, Xu L, Bi Q, Surve S, Ernst M, et al. Passivated contacts to laser doped $\mathrm{p}^{+}$and $\mathrm{n}^{+}$regions. Solar Energy Materials and Solar Cells. 2015;40:38-44. http://dx.doi.org/10.1016/j.solmat.2015.03.026.

13 Zanesco I, Moehlecke A. Analysis of the silicon dioxide passivation and forming gas annealing in silicon solar cells. In: Proceedings of the SWC 2015 ISES Solar World Congress; 20I5; Daegu, Coreia do Sul. Germany: ISES; 20I5. p. I-9.

14 Crestani T, Zanesco I, Moehlecke A, Razera R A Z, Aquino J, Model JCM, et al. Desenvolvimento do campo retrodifusor seletivo de alumínio e boro em células solares de silício. In: Anais VI Congresso Brasileiro de Energia Solar (VI CBENS); 2016; Belo Horizonte. Belo Horizonte: ABENS; 2016.

15 Kern W. The evolution of silicon wafer cleaning technology. Journal of the Electrochemical Society. 1990; I37:1887I891.

16 Costa RC. Desenvolvimento de processos industriais de fabricação de células solares bifaciais em silício CZ [dissertação de mestrado]. Porto Alegre: Programa de Pós-graduação em Engenharia e Tecnologia de Materiais, Pontifícia Universidade Católica do Rio Grande do Sul; 2009.

17 Zanesco I, Moehlecke A. Processo de difusão de dopantes em lâminas de silício para a fabricação de células solares. Patente PII 2030606, BR IO 2012030606 9. 2012 Nov. 30.

18 Zhao J, Green MA. Optimized antireflection coatings for high-efficiency silicon solar cells. IEEE Transactions on Electron Devices. 1991;38(8): 1925-1934. http://dx.doi.org/10.1 109/16.119035.

Recebido em: 8 Set. 2016

Aceito em: 23 Nov. 2016 